\title{
HUBUNGAN PERAN SERTA KADER DENGAN CAKUPAN KUNJUNGAN PENIMBANGAN BALITA KE POSYANDU
}

\author{
Soleh Bastaman *, Mokh.Firman Ismana **, Sigit Seno ***
}

\begin{abstract}
ABSTRAK
Posyandu merupakan kegiatan oleh dan untuk masyarakat, akan menimbulkan komitmen masyarakat, terutama para ibu, dalam menjaga kelestarian hidup serta tumbuh kembang anak.Peran serta atau keikutsertaan kader Pos Pelayanan Terpadu melalui berbagai organisasi dalam upaya mewujudkan dan meningkatkan pembangunan kesehatan masyarakat desa harus dapat terorganisir dan terencana dengan tepat dan jelas. Tujuan penelitian ini adalah untuk mengetahui hubungan peran serta kader dengan cakupan kunjungan penimbangan balita ke posyandu di UPT puskesmas plered kabupaten Cirebon tahun 2012. Penelitian ini bersifat deskriptif analitik dengan mengunakan metode pendekatan cross sectional.populasi dalam penelitian ini yaitu semua kader posyandu yang ada wilayah kerja UPT Puskesmas Plered Kabupaten Cirebon, sedangkan sampel diambil dari kader yang ada di posyandu sebanyak 57 kader dari populasi sebanyak 133 kader, cara pengambilannya menggunakan tehnik secara Proposional Random Sampling serta di lakukan uji statistic chi square dengan batas kemaknaan $\alpha=0,05$. Hasil penelitian menunjukan bahwa peran serta kader di posyandu yang ada di wilayah kerja UPT Puskesmas plered sebesar 77,2 \% menyatakan baik dan terdapat hubungan yang bermakna antara peran serta kader dengan cakupan kunjungan penimbangan balita ke posyandu di UPT Puskesmas Plered.
\end{abstract}

Kata Kunci : Peran Serta Kader, Cakupan Kunjungan Penimbangan Balita

\begin{abstract}
IHC is an activity by and for the community, will lead to commitment to the community, especially the mothers, in preserving the life and growth and development or participation anak. Actor and Integrated Service Post cadre through various organizations in efforts to create and enhance rural health development should be organized and planned precisely and clearly. The purpose of this study was to determine the relationship and the role of cadres with infants weighing coverage of the visit to the UPT clinic posyandu Plered Cirebon district in 2012. This research is descriptive method by using the Analytic cross sectional.populasi approach in this research that all existing posyandu working area Plered Cirebon UPT Health Center, while samples taken from the existing cadre in posyandu as many as 57 cadres, how to use the technique of extraction is Proportional Random Sampling and testing done by chi square statistic with significance limit $\alpha=0.05$. The results showed that the participation of cadres in existing posyandu UPT Health Center in the work area by $77.2 \%$ Plered good state and there is a significant association between the role of the cadre with the coverage of infants weighing visit to Posyandu Plered UPT Health Center.
\end{abstract}

Keywords : Participation Kader, Toddler Weighing Coverage Visits

\footnotetext{
* Staf Pengajar Program Studi S1 Kesehatan Masyarakat STIKes Cirebon

** Staf Pengajar Program Studi S1 Kesehatan Masyarakat STIKes Cirebon

*** Alumni PSKM STIKes Cirebon Lulus Tahun 2013
} 


\section{PENDAHULUAN}

Pembangunan dibidang kesehatan ini lebih diarahkan pada upaya dalam menurunkan angka kematian bayi, anak balita dan angka kelahiran. Sesuai dengan tujuan pembangunan kesehatan yaitu "Meningkatkan kesadaran, kemauan,kemampuan hidup sehat bagi setiap orang agar terwujud derajat kesehatan masyarakat yang optimal".Puskesmas adalah suatu organisasi kesehatan fungsional yang merupakan pusat pengembangan kesehatan masyarakat yang juga membina peran serta masyarakat disamping memberikan pelayanan secara menyeluruh dan terpaku kepada masyarakat di wilayah kerjanya dalam bentuk kegiatan pokok. $^{1}$

Secara operasional, ditingkat desa/kelurahan, upaya untuk menurunkan angka kematian bayi, balita dan angka kelahiran terutama dilakukan melalui Posyandu. ${ }^{2}$ Posyandu merupakan kegiatan oleh dan untuk masyarakat, akan menimbulkan komitmen masyarakat, terutama para ibu, dalam menjaga kelestarian hidup serta tumbuh kembang anak. Posyandu juga merupakan suatu forum komunikasi, ahli teknologi dan pelayanan kesehatan masyarakat oleh dan untuk masyarakat yang mempunyai nilai strategis untuk mengembangkan sumber daya manusia sejak dini. ${ }^{1}$

Posyandu tersebar di lebih dari 70.000 desa di indonesia. Pada tahun 2010, diperkirakan sekitar 91,3\% anak 6-11 bulan dan 74,5\% balita di bawa ke posyandu sekurang-kurangnya satu kali selama enam bulan terakhir. ${ }^{2}$ Jenis kegiatan posyandu dibagi menjadi 2 , meliputi lima kegiatan Posyandu atau yang dikenal dengan Panca Krida Posyandu dan Tujuh Kegiatan Posyandu atau yang disebut dengan Sapta Krida Posyandu. Lima Kegiatan Posyandu (Panca Krida Posyandu) meliputi kesehatan ibu dan anak (KIA), Keluarga Berencana (KB), immunisasi, peningkatan gizi, dan penanggulangan diare, sedangkan Tujuh Kegiatan Posyandu (Sapta Krida Posyandu) meliputi Lima Kegiatan Posyandu (Panca Krida Posyandu) ditambahkan dengan sanitasi dasar dan penyediaan obat esensial. Salah satu kegiatan pningkatan gizi adalah penimbangan. ${ }^{2}$

Supriasa menyatakan cakupan penimbangan (D/S) di posyandu adalah jumlah anak balita yang datang ke posyandu dan baru pertama sekali ditimbang pada periode waktu tertentu yang dibandingkan dengan jumlah anak balita yang berada di wilayah posyandu periode waktu yang sama. Hasil cakupan penimbangan merupakan salah satu alat untuk memantau gizi balita yang dapat dimonitor dari berat badan hasil penimbangan yang tercatat di $\mathrm{KMS}^{3}$

Dalam pergerakannya posyandu di motori oleh para kader terpilih di wilayah sendiri yang terlatih dan terampil untuk melaksanakan kegiatan rutin di posyandu maupun di luar hari buka posyandu.Kader posyandu bertanggung jawab terhadap masyarakat setempat serta pimpinanpimpinan yang ditunjuk oleh pusat pelayanan kesehatan. Diharapkan mereka dapat melaksanakan petunjuk yang diberikan oleh para pembimbing dalam jalinan kerjasama dari sebuah tim kesehatan. ${ }^{4}$

Peran serta atau keikutsertaan kader Pos Pelayanan Terpadu melalui berbagai organisasi dalam upaya mewujudkan dan meningkatkan pembangunan kesehatan masyarakat desa harus dapat terorganisir dan terencana dengan tepat dan jelas. Beberapa hal yang dapat atau perlu dipersiapkan oleh kader seharusnya sudah dimengerti dan dipahami sejak awal oleh kader posyandu. Karena disadari atau tidak keberadaan posyandu adalah sebuah usaha untuk meningkatkan. kesejahteraan masyarakat. Upaya posyandu yang telah ada dan telah berjalan selama ini mampu lebih ditingkatkan dan dilestarikan. ${ }^{5}$

Jumlah Posyandu di Kabupaten Cirebon adalah 2480 Posyandu terdiri dari Posyandu Mandiri 24, Posyandu Purnama 211, Posyandu Madya 559, Posyandu Pratama 1686, UPT Puskesmas Plered merupakan salah satu instansi yang menyediakan pelayanan kesehatan tingkat dasar di wilayah Kabupaten Cirebon dengan wilayah kerja meliputi 6 desa dengan 
jumlah posyandu 39 dan jumlah kader 133 orang. Berdasarkan laporan tahunan tentang cakupan D/S di Posyandu wilayah kerja UPT Puskesmas Plered pada tahun 2011 sebesar 82\% sedangkan target pencapaian D/S adalah $85 \%$ di lihat dari data diatas bahwa cakupan D/S pada tahun 2011 belum mencapai target yang di inginkan. Tujuan dalam penelitian ini untuk mengetahui hubungan peran serta kader dengan cakupan kunjungan penimbangan balita ke posyandu di Wilayah Kerja UPT Puskesmas Plered Kabupaten Cirebon Tahun 2012

\section{METODE PENELITIAN}

Penelitian ini merupakan penelitian deskriptif analitik metode yang menggambarkan keadaan yang ada pada objek penelitian saat dilakukan dengan menggunakan rancangan cross sectional dimana populasi diamati pada waktu yang sama. ${ }^{6}$ Dalam penelitian ini populasinya adalah semua kader posyandu yang ada di wilayah kerja UPT Puskesmas Plered Kabupaten Cirebon sejumlah 133 kader pada tahun 2012

$$
\begin{aligned}
& \text { Cara perhitungan besar sampel menggunakan rumus yaitu : } \\
& n=\frac{N}{1+N d^{2}} \\
& n=\frac{133}{1+(133) 0,1^{2}} \\
& n=\frac{133}{1+1,33} \\
& \mathrm{n}=\frac{133}{2,33} \\
& \mathrm{n}=57 \\
& \begin{array}{l}
\text { Keterangan : } \\
\mathrm{n} \quad=\text { Besarnya Sampel. } \\
\mathrm{N} \quad=\text { Ukuran Populasi. } \\
\mathrm{d} \quad \text { = Delta atau presisi absolut (ketepatan yang dinginkan) yaitu persenn kelonggaran ketidaktelitian karena kesalahan }
\end{array} \\
& \quad \text { pengambilan sampel yang masih dapat ditolerir, (10\%). }
\end{aligned}
$$

Dengan jumlah populasi sebanyak 133 kader maka perhitungan jumlah sampel yang di perlukan berdasarkan rumus diatas adalah 57 kader. Tehnik pengambilan sampel menggunakan proposional random sampling.

Instrumen penelitian menggunakan lembar Kuesioner Data peran serta kader di peroleh dengan cara wawancara langsung ke pada kader dalam pengumpulan data peneliti dibantu oleh 5-6 pengumpul data. Disesuaikan dengan jumlah kader pada saat pelaksanaan posyandu setiap desa. Data sekunder diperoleh dari laporan Puskesmas Plered tentang data jumlah cakupan kunjungan penimbangan balita ke posyandu. Analisis data terdiri dari analisis univariat dan bivariat, analisis univariat dilakukan terhadap tiap variable dari hasil penelitian. Dalam analisa ini hanya menghasilkan distribusi dan persentase dari tiap variabel. Analisis bivariat dilakukan melalui uji statistic Chi-square. 


\section{HASIL PENELITIAN \\ Peran Serta Kader}

Tabel 1 Distribusi Frekuensi Peran Serta Kader

\begin{tabular}{|c|c|c|c|}
\hline No & Lingkungan & Jumlah & $\%$ \\
\hline 1 & Kurang baik & 13 & $22,8 \%$ \\
\hline 2 & Baik & 44 & $77,2 \%$ \\
\hline & Jumlah & 57 & 100 \\
\hline
\end{tabular}

Berdasarkan tabel diatas, diketahui bahwa responden atau kader posyandu yang berada di wilayah kerja UPT Puskesmas Plered Kabupaten Cirebon, yang peran sertanya kurang sebanyak 13 orang $(22,8 \%)$, sedangkan yang peran sertanya baik sebanyak 44 orang $(77,2 \%)$.

\section{Cakupan Penimbangan Balita Ke Posyandu}

Tabel 2 Distribusi Frekuensi Menurut Cakupan Kunjungan Penimbangan Balita Ke Posyandu

\begin{tabular}{llcc}
\hline No & Cakupan Kunjungan Penimbangan & Jumlah & $\%$ \\
\hline 1 & Tidak tercapai & 10 & $17,5 \%$ \\
2 & Tercapai & 47 & $82,5 \%$ \\
\hline \multirow{2}{*}{ Jumlah } & 57 & 100 \\
\hline
\end{tabular}

Berdasarkan tabel diatas diperoleh informasi bahwa dari 57 responden menunjukkan bahwa cakupan kunjungan penimbangan balita ke posyandunya yang tidak tercapi sebanyak 10 responden $(17,5 \%)$ sedangkan yang tercapai 47 responden $(82,5 \%)$.

\section{Hubungan Peran Serta Kader Dengan Cakupan Kunjungan Penimbangan Balita Ke posyandu.}

Tabel 3 Hubungan Peran Serta Kader Dengan Cakupan Kunjungan Penimbangan Balita Ke posyandu

\begin{tabular}{lccccccc}
\hline \multirow{2}{*}{$\begin{array}{c}\text { Peran Serta } \\
\text { Kader }\end{array}$} & \multicolumn{2}{c}{ Cakupan Penimbangan Balita } & & \multicolumn{2}{c}{ Total } & P Value \\
\cline { 2 - 6 } & \multicolumn{2}{c}{ Tidak Tercapai } & \multicolumn{2}{c}{ Tercapai } & & \\
\cline { 2 - 6 } & $\mathrm{n}$ & $\%$ & $\mathrm{n}$ & $\%$ & $\mathrm{n}$ & $\%$ & \\
\hline Kurang Baik & 6 & $46,2 \%$ & 7 & $53,8 \%$ & 13 & $100 \%$ & 0,008 \\
\hline Baik & 4 & $9,1 \%$ & 40 & $90,9 \%$ & 44 & $100 \%$ & \\
\hline Total & 10 & $17,5 \%$ & 47 & $82,5 \%$ & 57 & $100 \%$ \\
\hline
\end{tabular}

Perbedaan proporsi tingkat peran serta kader dengan cakupan penimbangan balita ke posyandu dan setelah dilakukan uji hipotesis melalui uji statistik Chi-Square dengan batas kemaknaan $\alpha=0,05$ diperoleh nilai $\mathrm{P}=0,008$ terdapat hubungan yang signifikan atau dapat disimpulkan bahwa ada hubungan antara peran serta kader dengan cakupan penimbangan balita ke posyandu. 


\section{PEMBAHASAN \\ Peran Serta Kader}

Berdasarkan hasil penelitian diketahui bahwa responden atau kader posyandu yang berada di wilayah kerja UPT Puskesmas Plered Kabupaten Cirebon, yang peran sertanya kurang sebanyak 13 orang $(22,8 \%)$, sedangkan yang peran sertanya baik sebanyak 44 orang $(77,2 \%)$. Sehingga bisa diketahui bahwa peran serta kader di wilayah kerja UPT Puskesmas Pered Kabupaten Cirebon sudah cukup baik.

Peran serta merupakan suatu bentuk perilaku nyata. Oleh karena itu kajian mengenai faktor yang mempengaruhi peran sama dengan faktor yang mempengaruhi perilaku. Dengan demikian peran dipengaruhi oleh faktor pengetahuan dan sikap, pengalaman, keyakinan, sosial, budaya dan sarana fisik. Pengaruh atau rangsangan itu bersifat internal dan eksternal dan diklasifikasikan menjadi faktor yang mempengaruhi perilaku. Faktor perilaku meliputi faktor predisposisi (predisposing factors), faktor pemungkin (enabling factors), dan faktor pendorong (reinforcing factors). Faktor predisposisi merupakan faktor internal yang ada pada diri individu, keluarga, kelompok atau masyarakat yang mempermudah individu untuk berperilaku seperti pengetahuan, sikap, nilai, persepsi, dan keyakinan. Faktor pemungkin adalah faktor yang memungkinkan berperilaku, tersedianya sumberdaya, keterjangkauan, rujukan, dan keterampilan. Faktor penguat merupakan faktor yang menguatkan perilaku, seperti sikap dan keterampilan, teman sebaya, orangtua, dan majikan. ${ }^{7}$

Peran serta atau keikutsertaan kader Pos Pelayanan Terpadu melalui berbagai organisasi dalam upaya mewujudkan dan meningkatkan pembangunan kesehatan masyarakat desa harus dapat terorganisir dan terencana dengan tepat dan jelas. Beberapa hal yang dapat atau perlu dipersiapkan oleh kader seharusnya sudah dimengerti dan dipahami sejak awal oleh kader posyandu. Karena disadari atau tidak keberadaan posyandu adalah sebuah usaha untuk meningkatkan. kesejahteraan masyarakat. Upaya posyandu yang telah ada dan telah berjalan selama ini mampu lebih ditingkatkan dan dilestarikan. ${ }^{5}$

\section{Cakupan Penimbangan Balita Ke Posyandu}

Berdasarkan hasil penelitian diperoleh informasi bahwa dari 57 responden menyatakan bahwa cakupan kunjungan penimbangan balita ke posyandunya tidak tercapai sebanyak 10 responden $(17,5 \%)$ sedangkan yang tercapai 47 responden $(82,5 \%)$. Dengan perhitungan rata - rata tiap posyandu memiliki 5 kader dapat disimpulkan bahwa 2 posyandu cakupan penimbangan balitanya belum tercapai.

Penimbangan adalah pengukuran anthropometri (pengukuran bagian-bagian tubuh) yang umum digunakan dan pengukuran kunci yang memberikan petunjuk nyata dari perkembangan tubuh yang baik maupun yang buruk. Pengukuran anthropometri merupakan salah satu metode penentuan status gizi secara langsung. Berat badan merupakan ukuran suatu pencerminan dari kondisi yang sedang berlaku. ${ }^{8}$

Berat badan anak ditimbang sebulan sekali mulai umur 1 bulan hingga 5 tahun di posyandu. Supriasa menyatakan cakupan penimbangan balita di posyandu adalah jumlah anak balita yang datang ke posyandu dan baru pertama kali ditimbang pada periode waktu tertentu yang dibandingkan dengan jumlah anak balita yang berada di wilayah posyandu pada periode waktu yang sama. Hasil cakupan penimbangan merupakan salah satu alat untuk memantau gizi balita yang dapat dimonitor dari berat badan hasil penimbangan yang tercatat di dalam KMS. 


\section{Hubungan Peran Serta Kader Dengan Cakupan Penimbangan Balita Ke Posyandu}

Berdasarkan uji statistik diperoleh nilai $\mathrm{P}=0,008$ yang artinya ada hubungan yang signifikan antara peran serta kader dengan cakupan kunjungan penimbangan balita ke posyandu. Dari hasil penelitian diperoleh informasi bahwa dari 57 responden menunjukkan bahwa responden yang menyatakan peran serta kader kurang baik dan cakupan penimbangan balita tidak tercapai sebanyak 6 orang $(46,2 \%)$ dan tercapai sebanyak 7 orang $(53,8 \%)$. Sedangkan responden yang menyatakan peran serta kader baik dan cakupan penimbangan balita tidak tercapai sebanyak 4 orang $(9,1 \%)$ dan tercapai sebanyak 40 orang $(90,9 \%)$.

Hasil ini sejalan dengan penelitian yang di lakukan oleh Zal Fitriyah dengan judul Peran Serta Kader Posyandu dalam Upaya Peningkatan Status Gizi Balita di Posyandu Kelurahan Titi Papan tahun 2012. Bahwa nilai dimensi berwujud P Value $=0,004<\alpha=0,05$, yang artinya ada hubungan antara peran serta kader dengan cakupan kunjungan penimbangan balita ke posyandu.

Peran serta kader berhubungan dengan cakupan kunjungan penimbangan balita ke posyandu di karenakan kader adalah bagian dari masyarakat yang berhubungan langsung dengan masyarakat dalam setiap penyelenggaraan posyandu sehingga masyarakat akan lebih mudah dalam melakukan komunikasi dengan kader di bandingkan dengan petugas.

\section{SIMPULAN}

\section{Peran Serta Kader}

Sebagian besar kader $(77,2 \%)$ diwilayah UPT Puyskesmas Plered mempunyai peran serta yang baik

2. Cakupan Kunjungan Penimbangan Balita Ke Posyandu

Cakupan kunjungan penimbangan balita ke posyandunya tidak tercapai sebanyak 10 responden $(17,5 \%)$.

3. Berdasarkan uji statistik diperoleh nilai $\mathrm{P}=0,008$ yang artinya ada hubungan yang signifikan antara peran serta kader dengan cakupan kunjung penimbangan balita ke posyandu.

\section{SARAN}

\section{Saran Bagi Dinas Kesehatan Kabupaten Cirebon}

1) Meningkatkan Kemampuan pengetahuan dan keterampilan kader melalui pelatihan kader kesehatan.

2) Mengembangkan rewards system antara lain dengan :

(1) Memberi insentif secara rutin bersumber dari anggaran dana alokasi umum desa

(2) Memberi piagam penghargaan setiap tahun pada hari besar nasional seperti pada hari kemerdekaan

(3) Menyediakan perlengkapan/sarana/fasilitas yang memadai.

\section{Saran Bagi Puskesmas}

1) Memberi kemudahan dan keringanan untuk kepentingan pribadi kader seperti setiap berobat ke Puskesmas secara gratis.

2) Petugas puskesmas harus lebih aktif lagi dalam berkomunikasi dengan masyarakat.

3) Pembuatan jadwal rutin untuk pelatihan kader di karenakan pada saat penelitian banyak kader yang menyatakan kurang dalam pelatihan kader sehingga tidak sedikit kader baru yang belum mendapatkan pelatihan kader kesehatan.

\section{Saran Bagi Kader}


1. Kader hendaknya bekerja secara ikhlas agar tugas yang diembannya bukan merupakan suatu beban tapi sebagai suatu pengabdian.

2. Dalam melakukan pelayanan kepada masyarakat diharapkan melakukan pelayanan yang ramah karena kader merupakan ujung tombak bagi masyarakat.

\section{DAFTAR PUSTAKA}

1. Departemen Kesehatan RI, [Diakses tanggal 2 Mei 2012]; Diunduh dari http://ktiskripsi.com/.

2. Direktorat Bina Gizi, Buku Panduan Kader Posyandu, Jakarta; Kemenkes RI,2011.

3. Anonim. Pengertian Penimbangan secara Umum; [Diakses tanggal 6 Mei 2012]; diunduh dari http://staff.blog.ui.ac.id/tyarm/2009/05/20/.

4. Airin. Posyandu Merupakan Garda Depan Kesehatan Balita. [Diakses tanggal 6 Mei 2012]. Diunduh dari http://www.rakyatmerdeka.co.id

5. Zulkifli. Posyandu dan Kader Kesehatan. [Diakses tanggal 15 Desember 2011]. Diunduh dari http://library.usu.ac.id

6. Suharsimi Rikunto, Prosedur Penelitian Suatu Pendekatan Praktik, Jakarta :Rineka Cipta ; 2006.

7. Suliha Zalfitriyah. Peran serta Kader Posyandu Dalam Upaya Peningkatan Status Gizi Balita Di Posyandu Kelurahan Titipapan tahun 2012.Skripsi; tidak dipublikasikan : 2012

8. Anonim, Artikel penimbangan Balita Di posyandu [Diakses tanggal 10 Mei 2012]; Diunduh dari http://www.mediaindonesia.com/read/2009/12/20/112568/92/14. 